\title{
ALIGNING ICT4D WITH THE COMMUNITY ENGAGEMENT GOALS OF UNIVERSITIES IN SOUTH AFRICA ${ }^{1}$
}

Jane, an academic staff member of a university based in the Eastern Cape Province of South Africa, had been involved in Information and Communication Technology for Development (ICT4D) research for many years. Jane wanted to apply for academic promotion to an Associate Professor position at her institution. In order to be promoted to an Associate Professor level, Jane was required to demonstrate a certain level of competency (Exhibit 1) in three core activities of South African universities, namely teaching and learning, research and community engagement. She was confident about her ability to meet the promotion criteria with respect to her teaching and research activities. However, she was uncertain about the degree to which her activities satisfied the criteria for community engagement.

Located in the Eastern Cape Province (Exhibit 2), Jane’s university served students that were predominantly categorized as historically disadvantaged and underprivileged. As a result, the university could not ignore its role of serving the community that surrounded it. Over the years, the university had been placing increasing pressure on academic staff to contribute to the community engagement imperatives of the institution. The challenge she faced was that different scholars had different views of what community engagement actually meant.

Jane had implemented several ICT4D projects over the years and had always reported her projects as a form of community engagement. However, after attending a community engagement workshop, she became aware that community engagement was a more complex concept than she had initially understood it to be. Although she had generated many research outputs based on the studies she had undertaken, few of the initiatives she had been involved in had been sustained long after she had achieved her research outcomes. Jane reviewed the last ICT4D project she had undertaken in a rural community (Exhibit 3) with the intention of evaluating whether the project could be used to support her contribution to the community engagement component in her submission to the Promotions Committee. She felt that if the project did not provide strong evidence of community engagement that is commensurate to the post she was applying for, she needed to review how she would undertake future ICT4D projects.

\footnotetext{
${ }^{1}$ Copyright (C) 2018, Jaquiline Mkombachoto, Naomi Isabirye, Mamello Thinyane. This case was prepared for the purpose of class discussion. Names and some information have been disguised. This case is published under a Creative Commons BY-NC license and originally appeared as a chapter in Transforming Society Using ICT: Contemporary Discussion Cases from Africa. Permission is granted to copy and distribute this case for noncommercial purposes, in both printed and electronic formats.
} 


\section{Community Engagement in Universities in South Africa}

Jane initiated her investigation by examining the nature of community engagement in universities in South Africa. This was followed by an investigation of ICT4D case examples that could potentially be used as a benchmark for community engagement. Jane's research revealed that in South African universities, community engagement constituted an integral part of learning. Universities were called upon to become socially responsible by providing expertise and infrastructure for community service programs. Community engagement was recognized as one of the three key activities underlying universities. She adopted a definition of community engagement as 'an experiential form of learning where researchers at universities learned by engaging with communities in a mutually beneficial manner' (Mkombachoto, 2017). The mutual benefit aspect of the definition of community engagement caught Jane's' attention. She wondered what constituted "mutual benefit" in community engagement and how it could be attained when implementing ICT4D projects.

As Jane read further, she discovered that for a long period of time, the South African education department had sought to ensure that knowledge generated by universities impacted on the social, cultural, and economic problems faced by the societies surrounding them. Hence in 1997, through the White Paper for Transformation of Higher Education, the South African Higher Education Act set out an agenda to transform universities from historically inequitable institutions of higher learning into educational systems that served both learners and communities. Through the aforementioned Act, community engagement became a priority in South African universities. Jane found that over the years, it had become recognized that community engagement was more than just the third pillar of a university. Community engagement added significance and context to the other two pillars of teaching and learning and research. She realized that community engagement had become an integral part of the assessment of the credentials of academic staff members. Community engagement activities were used to assess academic job applications, promotions and performance appraisals. Historically, community engagement in universities had been inclined towards community benefit, but there had been an emerging shift in thinking that recognized that it should be reciprocal in nature. Jane thus realized that for an academic researcher to be deemed to have achieved the goals of community engagement, both the community and the university involved would have had to have benefited.

Despite the emphasis placed on community engagement in South African universities, Jane realized that many academic staff members had struggled to attain a common understanding of what should constitute community engagement. Jane also discovered that, although universities had a mandate for community engagement, some of them only reflected it in their vision and mission statements. In essence, they lacked operational policies to help foster community engagement activities. So, academic researchers, like herself, were usually involved in community engagement projects that were mainly individual endeavors and were not strategically planned or coordinated at an institutional level. Jane also found that balancing teaching and learning and research with community engagement was a difficult task for many academic staff members. Many academics were comfortable with teaching and learning and research, but found it challenging to integrate these activities with community engagement. From a workshop Jane had attended, the presenter, who was also an esteemed scholar in the field of community engagement, cited several factors that characterized quality community engagement (Tapia, Gonzales \& Eliceui, 2005). These factors were:

- $\quad$ Effective satisfaction of the needs of the community (both short term and long term needs)

- $\quad$ Measurable outcomes on the quality of life of the community

- $\quad$ Creation of long term partnerships that formed the basis for future community engagement projects between the university and the community 
- $\quad$ Knowledge created, which informed research and ultimately contributed to the knowledge creation capacity of the academic researchers involved

- Integration into and alignment with the learning outcomes and assessment criteria of the students involved

Jane also became aware that although the aforementioned factors provided a benchmark for community engagement, community engagement presented itself in many other forms. For example, in the same workshop, it was stated that community outreach, community service, volunteerism and student internships were all considered to be acceptable forms of community engagement. What became clear was that community engagement could be measured in terms of the degree to which the needs of the learners, researchers and community members were balanced to achieve long term mutual benefit. The higher the degree of reciprocity, the higher the quality of community engagement. This was also evident in the assessment criteria for community engagement that was stipulated in her university's promotions policy (Exhibit 1). Having understood the nature of community engagement and what its goals were in South African universities, Jane proceeded to consider how the concept of community engagement related to ICT4D projects.

\section{ICT4D Research}

\section{Overview}

Jane had been involved in the implementation of some ICT4D projects and understood that the basic notion around the adoption of ICTs in underprivileged communities was based on the belief that ICTs had the potential to either socially or economically improve and contribute to the development of individuals, businesses and communities. Jane also knew that one of the many goals of ICT researchers was to help reduce the digital divide between underprivileged and privileged communities. Many ICT4D researchers saw ICTs as a means to uplift underprivileged communities by providing faster quicker information, social services and new economic opportunities. However, Jane was also aware of the growing number of scholars who criticized ICT4D projects for benefitting the researchers more than the communities concerned. Furthermore, some critics believed that research reports were often biased, and tended to favor the interests of researchers rather than communities. The field of ICT4D had also been criticized for being fragmented and uncoordinated and it had been argued that little progress had been made in achieving the goals of the discipline and that researchers were failing to learn from the experiences of others.

Nevertheless, Jane was also aware that ICT was recognized as a necessary tool in development, and that even the United Nations saw ICT as an important developmental tool. In fact, the most recent United Nations' Sustainable Development Goals had identified ICT as an important developmental tool that could help foster economic growth and alleviate poverty in developing countries. Jane's attention was particularly drawn to an article by Heeks (2009), which outlined three important characteristics of ICTs that addressed the needs of the poor. The article stated that such ICTs should be:

- Inclusive - ICT4D projects should provide opportunities and services that benefit all the members of the communities concerned.

- $\quad$ Enabling - ICT4D projects should be context specific and be in line with the realities of the community in which they are being implemented. 
- Focused - ICT4D projects should be undertaken in such a manner that they satisfy and serve the interests of the particular community where the technology is implemented.

Jane came to the realization that the consequence of aligning one's research activities with the requirements of community engagement was likely to result in ICT4D projects that satisfied the needs of the communities involved. Consequently, this alignment could help to address some of the criticisms that faced ICT4D.

\section{Community Engagement in Universities in South Africa and ICT4D}

After discovering this information, Jane made several deductions. Firstly, she realized that there was an overlap between the goals of community engagement at universities and the objectives of ICT4D research. The objective of ICT4D projects was to generate or enhance knowledge about ICTs in the context of socio-economic development, while making a contribution to the wellbeing of the communities through the use of ICTs. Similarly, community engagement principles emphasized that community building activities initiated by universities should also contribute to the enhancement of learning and knowledge through the betterment of communities. Therefore, conducting research according to community engagement principles required that the lessons learnt from the projects should inform ICT curricula and consequently improve the state of learning in the ICT4D research area.

Jane further recognized that both ICT4D objectives and community engagement goals encouraged the undertaking of projects that were sustainable in the long run. Whereas sustainability was one of the vital factors in the successful implementation of ICT4D projects, one of the goals in community engagement was to satisfy long term and not only immediate needs. These parallels reflected how both ICT4D and community engagement goals were aligned in terms of having long term positive impact on the communities. For such an outcome to be realized, ICT4D encouraged effective collaboration among the various stakeholders involved in the projects - which in this case included the community members and academic researchers. Similarly, community engagement goals encouraged the creation of long term partnerships as a goal for successful implementation of community engagement projects.

Jane also became aware that there were challenges that hindered ICT4D projects from attaining their goals. Many of these challenges could be addressed by applying community engagement principles. From her research, she had found that the application of ICTs had not always been successful in underprivileged communities. Technologies that had successfully contributed to positive outcomes in developed communities would not necessarily produce the same results in underprivileged communities. As a consequence, ICT4D projects that had been introduced in underprivileged communities often failed or only achieved partial success. Jane knew there was a need for academic researchers to understand that ICT was only an enabler for the problems faced by communities and not the solution itself. For an ICT4D project to serve its intended purpose, the real needs of communities needed to be well understood.

Jane also realized that many ICT4D projects had failed to be sustainable due to lack of resources. Many academic researchers involved in the implementation of ICT4D projects depended on donor funding. Once these funders left, ICT4D projects often failed to attract funding or the resources necessary to sustain the projects. Balancing the timelines and expectations of the various stakeholders in these projects could be very challenging. For example, donors might require rapid turnarounds, while students needed to conclude their involvement within the timeframes of their studies. In some cases, a university's involvement would not be sustained long enough for the community's needs to be fully addressed. Jane decided to round up her investigation by looking into two practical examples of ICT4D projects. The 
projects Jane selected were both ICT4D projects undertaken by academic researchers in underprivileged communities in South Africa.

\section{Outline of Cases}

The projects that were investigated were the Siyakhula Living Lab project and the Information and Communication Technology for Rural Education (ICT4RED) project.

\section{The Siyakhula Living Lab project}

The Siyakhula Living Lab project was initiated in 2005 with the aim of developing and field-testing a prototype of multifunctional, distributed communication platforms for marginalized communities in South Africa. The project was launched after an intensive needs assessment that lasted almost three years. The initiative was launched under the auspices of the University of Fort Hare, Rhodes University and other stakeholders. The project was initially funded by Telkom, a partly state owned telecommunications provider in South Africa. Over the years, further funding had been obtained from other organisations.

One of the primary requirements of the project was that a local loop access was deployed. This was the basis upon which the community would gain access to ICT networks. Worldwide Interoperability for Microwave Access (WiMAX) technologies were used to build the local loop while VSAT technology enabled internet access (Sieborger, \& Terzoli, 2009)

The project was piloted in a single school, where a 'train-the-trainer' approach was implemented. Using this approach, teachers and community champions were identified and provided with computer skills training. They were then mentored to deliver the same training to interested community members. Thereafter, the project expanded the ICT network access to more than 17 schools in Dwesa and the user base for the Siyakhula Living Lab grew to approximately 200 community members and 4500 learners in the 17 participating schools.

In 2009 the project started engaging students at the University of Fort Hare and Rhodes University to develop and test applications to serve the needs of the Dwesa community. The Siyakhula Living Lab project benefited the Dwesa community in a variety of ways. Firstly, many schools in Dwesa were provided with computers and internet access. The access to computers and the internet was extended to members outside of the schools. Community members were provided with computer skills training and were able to gain improved access to information through the internet. With the vast majority of rural communities in South Africa not having internet access and not knowing how to use ICTs to enhance their lives, the Siyakhula Living Labs made progress in improving the quality of life of the involved community members.

Collaboration between the researchers and the community involved the nurturing of a long standing relationship. The project team involved the community members in critical project decisions. Although many of the community members had never used computers prior to the inception of the project, the feeling of being included and consulted made them excited about the project. To establish a more concrete relationship with the community, the project team rented a house in Dwesa and would ensure that team members stayed there on a rotational basis.

The project had been recognised for making a noteworthy impact on the Dwesa community. For example, Jane discovered that one of the project leaders had been awarded the Distinguished Vice- 
Chancellors' Community Engagement Award by his university, for his exceptional contribution to mutually beneficial and socially relevant projects. Students' learning outcomes were also satisfied through the project as many post graduate research projects had been founded on the project. In terms of informing research, the Siyakhula Living Labs had resulted in many research publications over the years that other projects could learn from. One of the community members who acquired ICT skills from Siyakhula was the subject of a documentary that was aired on national television in order to inspire other people in underprivileged communities to participate in similar projects. To keep the various stakeholders informed about the status of the project, the Siyakhula Living Lab project team hosted an annual workshop where they discussed the future direction of the project. With the need for expansion came the need for further funding. The initial project at Dwesa had been funded by Telkom, but if the project was to expand further, the project team believed the government would have to come on board.

\section{The Information and Communication Technology for Rural Education project}

Jane reviewed a number of resources pertaining to the ICT4RED project, one of which was a book (Herselman \& Botha, 2014) that had documented the project extensively. She also consulted one of the project leaders to gain further insight into the project. The ICT4RED project had been launched in a remote rural town in the Eastern Cape Province in 2012, and was aimed at introducing appropriate Information and Communication Technology (ICT) devices and infrastructure into resource constrained schools. The goal was to integrate ICTs in a manner that enhanced teaching and learning and supported effective and sustained integration into the teaching and learning activities of schools. One of the envisioned outcomes was development of contextual frameworks, model guidelines and tools to inform similar initiatives. The South African Department of Science and Technology (DST), the South African Department of Basic Education (DBE), the Eastern Cape Department of Education (ECDoE) and the Department of Rural Development and Land Reform (DRDLR) were all external stakeholders of the project. The project was managed by the Meraka Institute, which operates as a unit of the Council for Scientific and Industrial Research (CSIR), and also involved researchers and post graduate students from several universities in South Africa including three Eastern Cape based universities: Nelson Mandela Metropolitan University, Rhodes University and the University of Fort Hare.

The project was implemented in successive phases, with the initial phase focusing on research and planning. This phase involved intensive desktop research into the failures and successes of previous ICT educational initiatives around the world. The planning phase resulted in the adoption of the InterAmerican Development Bank Conceptual Framework for the underlying implementation. The framework was later adapted to better reflect the context of resource constrained schools (Exhibit 4). Thereafter, the project progressed to the pilot phase.

The Arthur Mfebe Senior Secondary School served as the project's pilot site. During the pilot phase of the project, the project team endeavored to garner the support of education district officials, the headmaster and deputy headmaster, and the school's governing body. Project champions were identified and a workshop was held to help the stakeholders understand their roles in the project. A teacher training programme was initiated where teachers were equipped with the knowledge and skills required to assist them with integrating ICT into their teaching. The teachers at the school were provided with 7 inch tablets that were offered as part of an 'Earn as you Learn' incentive. In order to gain full ownership of the devices, the teachers were required to complete the training programme, which included homework tasks. 
In December 2012, the pilot phase came to an end and the project was officially launched. Arthur Mfebe Senior Secondary School was awarded two Mobikits which each housed 10 tablets. These tablets were allocated to the grade 12 learners, who were regularly given an opportunity to take the tablets home and use them for learning purposes. In addition, the teachers' 7 inch tablets were upgraded to 10 inch tablets, and their old devices were allocated to grade 12 learners. By mid-2013, the teachers at the pilot site had completed their training and had earned full ownership of the tablets. In addition, all the matric learners at the pilot site were issued with their own tablets. The subsequent phase of the project began and a further 144 teachers from the pre-selected 11 neighboring schools were also issued with tablets. The project progressed according to the illustration outlined in Exhibit 5.

Jane had consulted different stakeholders of the project, and had learned that the project team had emphasized intensive planning, monitoring and evaluation throughout the duration of the project. The underlying framework was adapted into a new framework that fit the context more appropriately (Exhibit 4). Stakeholder management had been a vital factor in the success of the project. The project team understood that for the project to succeed there was a need for full community buy-in. Therefore, not only did the project involve the teachers and learners who were directly benefiting from the project, the whole community including the parents and tribal leaders also participated in the project. Jane also learnt that the project had not only impacted the ICT4D research field through its local and international publications, but had also influenced the teaching discipline through the teacher training material that had been adopted for training teachers in ICT integration by other schools, both nationally and internationally. At the end of 2014, the project was documented in the form of a book (Herselman \& Botha, 2014). The book provided a comprehensive and insightful account of the project journey and the lessons learned. It detailed how the project was designed and implemented, and proposed an implementation framework for similar projects. Monitoring and evaluation mechanisms, teacher professional development, technical deployment considerations and change management, amongst other topics, were covered extensively in the book.

\section{Observations from the Case Studies}

Jane observed that sustainability, collaboration and effective needs assessment were critical issues in the implementation of ICT4D projects.

\section{Understanding User Needs}

Both projects demonstrated that it was important to understand user needs in order for a project to make a meaningful contribution to the community, the researchers and other external stakeholders. It proved essential to undertake an in-depth needs assessment process. Needs assessment for the Siyakhula Living Labs project had started 3 years before the project was initiated and continued throughout the project through ongoing consultation amongst the stakeholders. The ICT4RED project had also used in-depth desktop research as well as interviews prior to piloting the project. The project had been rolled out in phases, helping the team to modify the project according to lessons learnt in each phase. In the end, both ICT4D projects appeared to satisfy user needs - with users expressing satisfaction about the benefits. For both projects, obtaining user needs was not a once-off process, but a cyclic one that required time.

\section{Collaboration}

Collaboration was vital for the success of the projects that Jane reviewed. To ensure the projects' success, the needs of the various stakeholders had to be balanced, ensuring that they all felt valued in the project. In the ICT4RED project, the project team had realised the importance of the socio political 
structure of the community in order to ensure buy-in to the project. The tribal leaders and chiefs felt valued and were willing to participate in the project because they had been involved in the meetings. Through effective collaboration, relationships had been nurtured between the various stakeholders, encouraging long term partnerships. Project team members of the Siyakhula living labs project had maintained an ongoing physical presence in the community. Their field visits had been frequent and lengthy. They also engaged a wide array of stakeholders in the community. The sustained financial support from the project funders also demonstrated how both project teams had effectively managed the relationships with the external stakeholders.

\section{Sustainability}

The last factor that Jane identified as being important for the success of ICT4D projects in communities was sustainability. Both financial and technological sustainability needed to be addressed to ensure success of the projects. The Siyakhula Living Labs project and the ICT4RED project had both received substantial funding over the years. The funding was sourced from either government organizations or partially state owned entities. Jane's project, on the other hand, had obtained its funding as a one-time research grant from an international organization. Although the projects she studied had depended on funding in order to acquire the infrastructure and technology to launch the initiatives, both were conducted in a manner that encouraged community ownership. With such sense of ownership in place, the community would potentially be motivated to sustain the activities and outcomes beyond the duration of the projects.

\section{Conclusion}

Jane had gained an understanding of the nature of community engagement in South African universities and had some insight into the measures that could contribute to sustainable and mutually beneficial ICT4D projects. She now needed to determine whether her project was ready to be presented to the committee as evidence of the requisite level of community engagement for the promotion. In comparison to the two cases she had reviewed, her project had not been sustained for very long. However, her project had generated a wealth of learning experiences. She decided to reflect deeply on her last project. Questions that Jane needed to answer with respect to her project included:

- Did her last project demonstrate the criteria for community engagement that was commensurate with the associate professor position?

- If not, how could she amend the way she conducted ICT4D research to qualify it for the required level of community engagement?

- With respect to the cases she reviewed, which factors contributed to their success in sustaining a mutually beneficial relationship between the researchers and the communities. 


\section{References}

Heeks, R. (2009). The ICT4D 2.0 Manifesto: Where Next for ICTs and International Development? Working Paper Series, Development Informatics. Retrieved October 14, 2017, from https://www.oecd.org/ict/4d/43602651.pdf

Herselman, M., and Botha, A. (2014). Designing and implementing an Information Communication Technology for Rural Education Development (ICT4RED) initiative in a resource constraint environment: Nciba School District, Eastern Cape, South Africa. CSIR, Pretoria, South Africa.

Mkombachoto, J. (2017). A model for applying community engagement principles for successful implementation of Information and Communication Technology for Development Projects by Higher Education Institutions in South Africa. Masters Dissertation, University of Fort Hare, East London, South Africa.

Sieborger, I., and Terzoli, A. (2009). WiMAX for rural SA: The experience of the Siyakhula Living Lab. Proceedings of the Southern African Telecommunication Networks \& Applications Conference: A society enabled by Innovation and Applications. Stellenbosch, South Africa.

Tapia, M N; Gonzalez, A; Eliceui, P. (2005). K-12 Service Learning in Argentina. Washington University, Center for Social Development, St Louis. Retrieved October 14, 2017, from https://csd.wustl.edu/Publications/Pages/DisplayResultItem.aspx?ID1=551 


\section{Biography}

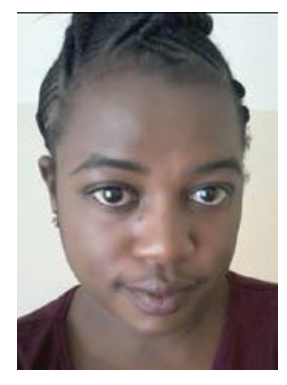

Jacquiline Mkombachoto holds a Masters of Commerce Degree in Information Systems from the University of Fort Hare, South Africa, where she also received her Honours Degree in the same field. For these two degrees, her principal research areas were the implementation of ICT4D in underpriviledged communities and Small Medium Enterprises (SME).

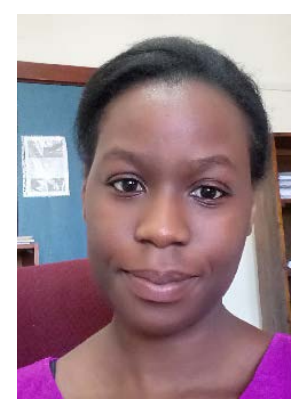

Naomi Isabirye holds a PhD in Information Technology from the Nelson Mandela Metropolitan University, South Africa. She is a senior lecturer at the University of Fort Hare, South Africa. Her research interests are in the fields of ICT4D, ecommerce and technology trust. She also has an interest in community engagement and serves as a community engagement coordinator in her academic department.

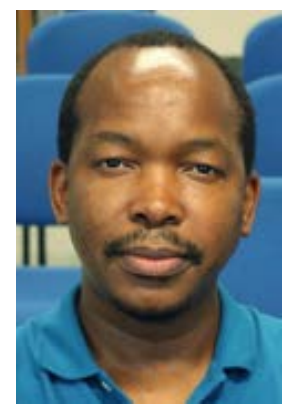

Mamello Thinyane holds a PhD in Computer Science from Rhodes University, South Africa. He is the former Head of the Telkom Centre of Excellence in Information and Communication Technologies for Development as well as an Associate Professor in the Department of Computer Science at the University of Fort Hare. He is passionate about technology innovation and community development. 


\section{Exhibit 1: An extract from the promotions policy at Jane's university relating to community engagement}

\section{Promotion criteria}

- $\quad$ An applicant must meet the minimum appointment criteria.

- A doctoral degree, irrespective of the discipline or field or exceptions made in terms of footnote 9 (which apply to appointment to this level, not promotion).

- A qualification in the assessment of learning at NQF Level 7/8, or an equivalent teaching qualification.

- $\quad$ Minimum of nine (9) points, with either teaching or research at Level 3 and the other at Level 2; alternatively, a minimum of nine (9) points with either teaching or research at Level 4.

\section{LEVEL DESCRIPTORS: COMMUNITY ENGAGEMENT}

Community engagement (CE) articulates the University's social responsibility/investment/development programme and refers to initiatives that link University activities to the community it serves, in particular partnerships aimed at addressing the social, cultural and economic development objectives of society. Teaching, research and management/ administrative skills are put to the service of the wider community. CE has both an "external" aspect (that highlights interaction with communities) and an "internal" aspect (that relates to the institution's teaching and learning and research needs). Aspects of community engagement might therefore overlap with other areas of competence, that is, teaching and learning, research and university service.

CE includes: (a) Volunteerism (altruistic engagement of students and staff in activities primarily benefiting the recipient community, with service provision as the primary goal); (b) Community outreach (engagement primarily focused on benefiting the community through delivering a particular service, but is generally initiated from within the institution); (c) Internships and co-operative education (activities where the student is the primary beneficiary and the goal is on student learning); (d) Service learning (activities where both the community and student are the primary beneficiaries, reciprocity being the central characteristic)

Society must be satisfied that the institution has made a difference to the community in which it is situated and the projects should comprise genuine social investment or social development initiatives, not marketing exercises. The measure of good CE should not be the level of income that is being generated, but the impact that the University has on society, especially on the communities within its immediate vicinity.

\section{Community Engagement Level 1}

Performance at Level 1 requires involvement in CE initiatives and may be demonstrated through meaningful contribution to any CE activity as defined, not necessarily in an organizational capacity. 


\section{Community Engagement Level 2}

Performance at Level 2 requires a greater level of involvement and/or responsibility than in Level 1. Indicators, in addition to those mentioned for Level 1, could include:

- $\quad$ Contribution to community development through community projects that impact on socioeconomic/living conditions in communities.

- $\quad$ Projects in which staff and students evidence a spirit of volunteerism.

- $\quad$ Initiatives that promote service learning and experiential learning.

- Involvement promotion of CE at departmental, faculty and/or institutional level.

\section{Community Engagement Level 3}

Performance at Level 3 requires involvement and evidence of leadership in CE activities Indicators, in addition to those mentioned for Level 2, could include:

- $\quad$ Demonstrated initiative and contribution to policy formulation.

- $\quad$ Creation and maintenance of linkages between UFH and employers, schools, industry and government agencies, and national and international universities.

- $\quad$ Representative of UFH on formal external bodies in either the public or private sector.

- $\quad$ Contribution towards teaching and research expertise for the development of the wider community.

- Administration of CE projects in the institution.

- $\quad$ Seeking opportunities for CE at the institution.

- $\quad$ Raising funds for CE initiatives.

\section{Community Engagement Level 4}

- $\quad$ Performance at Level 4 requires both internal and external recognition for involvement and leadership in CE initiatives. Indicators, in addition to those mentioned for Level 3, could include:

- $\quad$ Contribution to significant cross-directorate and/or cross-faculty developments.

- $\quad$ Significant contribution to resource development.

- $\quad$ Formal policy and/or curriculum development at national or international level.

- $\quad$ Involvement in the development of CE theory and policy.

- $\quad$ Participation at conferences and showcasing CE experiences to a wider audience.

- $\quad$ Evidence of recognition of involvement in CE, for example, publicity that projects generate, and requests to advise others on CE activities.

- $\quad$ Significant fundraising activity.

Source: University X (2012). Policy document for promotion of research and academic staff 


\section{Exhibit 2: Background of the Eastern Cape province}

The Eastern Cape, a South African Province, came into existence in 1994 and incorporated areas from the former Xhosa homelands of the Transkei and Ciskei. The Eastern Cape is considered the poorest province in South Africa in terms of poverty and education, just to mention a few. The capital city is Bhisho, but its two largest cities are Port Elizabeth (with Nelson Mandela Metropolitan University) and East London (with University of Fort Hare, East London campus). In terms of development, the province is still poor though it has 3 major car plants to support the region, and 4 well known universities in South Africa. The main problem of its state has been found in the educational sector, which has been criticised for poor primary and secondary education as the province struggles with a lack of schools, educators, and connecting infrastructure.

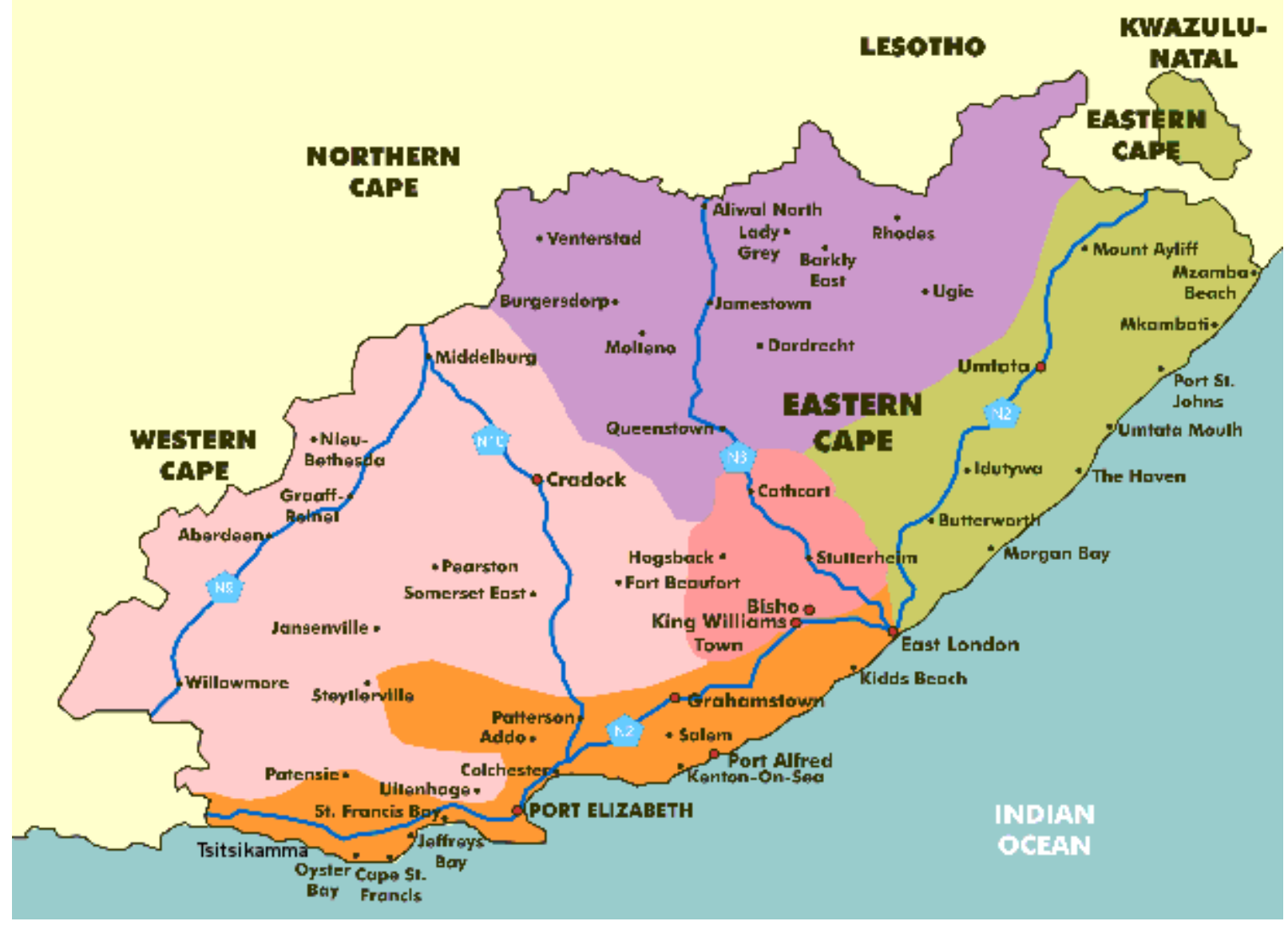

Figure 1: Map of the Eastern cape. (Source: Kaseve, K. (2017). Poverty Trends in South Africa 20062015: Highlights for the Eastern Cape. 16 pages. South Africa: Eastern Cape Socio Economic Consultative Council (ECSECC).) 


\section{Exhibit 3: An Overview of Jane's last ICT4D project (The aloe e-marketplace)}

\section{Background}

Jane's last project, the Aloe e-marketplace project aimed at developing and testing a voice based ecommerce platform within a rural farming context. The project emerged as a result of Jane's interest in rural agriculture. Jane believed ICTs had the potential to bridge the gap between rural farmers and buyers of their produce. Hence, she had begun to undertake research on how e-commerce could support the sale of agricultural goods. Her research had identified several challenges that rural farmers faced selling their produce. These challenges included the fact that their remote location gave them limited access to buyers and as a result, the buyers had enough bargaining power to influence the price of their produce. Jane was also aware that the buyers were often middlemen that subsequently sold their produce for much higher returns. Jane believed that e-commerce could bridge the gap between the farmers and potential buyers, and minimise the need for a middleman. This could result in farmers earning more for their produce. Jane had also been aware that in rural communities, farmers were typically older members of the population. As a consequence of the rising trends in urbanisation, many younger people had moved to the cities to seek other opportunities. The elderly rural farmers were not always literate, and few of them had Internet enabled devices, or the necessary skills to successfully exploit the potential opportunities that ecommerce could present. Jane had been collaborating with an IBM research group based in India, who had developed The Spoken Web, a voice driven technology platform that was aimed at providing information services to rural users. The research group's motivation for using voice as a medium for exchange was that it was accessible using the most basic mobile handsets and it did not require the users to be literate. The Spoken Web had been piloted in many different usage contexts in India, with positive results. Jane and the Spoken Web research group in India decided to pilot the Spoken Web in South Africa. After much consultation between Jane and the research group, they decided to test the use of The Spoken Web in the context of a voice based e-marketplace for a rural aloe harvesting community.

\section{The Intervention}

Jane investigated several rural communities that had been involved in the aloe trade. She contacted a few of them and eventually identified a farming community that was willing to participate with her to field test an e-marketplace to support their trade. The community was based in a small farming town called Albertinia, in the Western Cape Province of South Africa. Jane held discussions with the managing director of the aloe factory, as well as ten aloe harvesters and two farmers, to understand how they traded within their industry and how e-commerce could support their trade. Jane established that aloe harvesting was typically undertaken by farm labourers that lived and worked on large farms. They were employed as farm labourers, however, they worked independently as aloe harvesters. The aloe plant was a wild plant that grew on these farms, and was not a priority product of the farmers. Hence, there had been long standing agreements with labourers (who were also aloe harvesters) and the farm owners allowing them to harvest the aloe and sell it privately to the local aloe factory. The harvesters would then pay a small portion of their earnings to the farm owners in exchange for having been allowed to harvest from their farms.

Aloe harvesters would harvest the aloe leaves and drain the sap from the leaves into large drums. They indicated that the process of harvesting and filling the drums was a lengthy one, taking several days to 
complete. Once the drums had been filled, they would be heavy and, as the labourers did not own their own delivery vehicles, the farm owners would assist the labourers with delivery of the drums to the aloe factory. Jane observed that the process was very manual and inefficient. The labourers complained that the farms were large and they were not always able to reach the farm owners to notify them that there was a drum available for delivery. They mentioned that some parts of the farms did not have cell phone network coverage so often they could not reach the farmers telephonically. In addition, they would sometimes walk long distances to the farmers' home, and find that he was not present. Jane also found that many of the aloe harvesters were elderly men and women. Amongst the group of farm labourers that she met, some were not literate, one was visually impaired, and most could not speak English. Jane was also surprised to find that only a few of them had their own mobile phones. Many of them shared phones with family members.

Jane and the project team reflected on the conditions of the aloe harvesters and developed a voice based system that allowed asynchronous telephonic communication between the harvesters and the farmers. The system allowed harvesters to phone a number, then follow a set of voice prompts directing them to capture the number of drums they had filled and the location of the drums. The farmers could then phone in at any time to get a listing of the drums that had been filled. The system was accessible from any basic mobile or fixed line handset and did not require Internet access to function. The voice calls made by the participants were to a local fixed-line telephone number. The voice calls were then converted and routed through a gateway to the Spoken Web application, which was hosted in India. The Spoken Web application provided the business logic and speech recognition that enabled a user friendly call flow, and allowed the option of responding to prompts using speech or using the phones keypad.

The harvesters used the system for a period of eight weeks. During the eight weeks, the project team interacted with the pilot group to refine the system to a point where it was user friendly and the harvesters were able to use it effectively without any errors. The iterations included changes in the call flows, changes in the terms used and refining the voice recognition aspects of the system. Thereafter Jane held interviews with the users to reflect on their experience with the system. Jane received very positive feedback from the harvesters, who felt that, after all the technical concerns had been eliminated, they had found the system easy to use, and it brought a lot of convenience to their business. One harvester mentioned that before the system had been introduced, he used to walk an hour to get to the farmer's house and notify him of his harvest. The managing director of the aloe factory also stated that the system had massive scope in different applications for agriculture. He even suggested that the scope of the system could be extended to allow the aloe factory to use the listings that the farmer had been receiving for production and cash flow planning, arguing that he rarely knew how many drums would be delivered. If he had real time information about the harvests he could allocate his manufacturing resources more effectively, and forecast the remuneration of the harvesters better.

Unfortunately, Jane was not able to sustain the project for long after the pilot. The gateway that had been configured to route the calls to the Spoken Web had been requested for use by other projects in her department that were, at the time a higher priority. As a result, the Spoken Web aloe e-mark6etplace was suspended and the voice platform reallocated to another project. This was communicated with regret to the pilot group. Although the intention was to re-establish the project at a later stage using the lessons learned from the intervention, the researchers had not been able to secure the funding to do so.

Jane's initiative attracted much interest from the public. She had been invited to hold talks for the Eastern Cape Rural e-skills work group, as well as to present her project to the Eastern Cape Department of Rural 
Development and Agrarian Reform. Jane’s project also resulted in several research publications and eventually became the subject of her PhD thesis.

Source: Isabirye, N. (2015). A framework to enhance trust in voice based e-marketplaces accessed from mobile devices. Doctoral Thesis, Nelson Mandela University, Port Elizabeth. 


\section{Exhibit 4: The ICT4RED Framework}

\section{FINAL GOAL: IMPROVING LEARNING OUTCOMES}

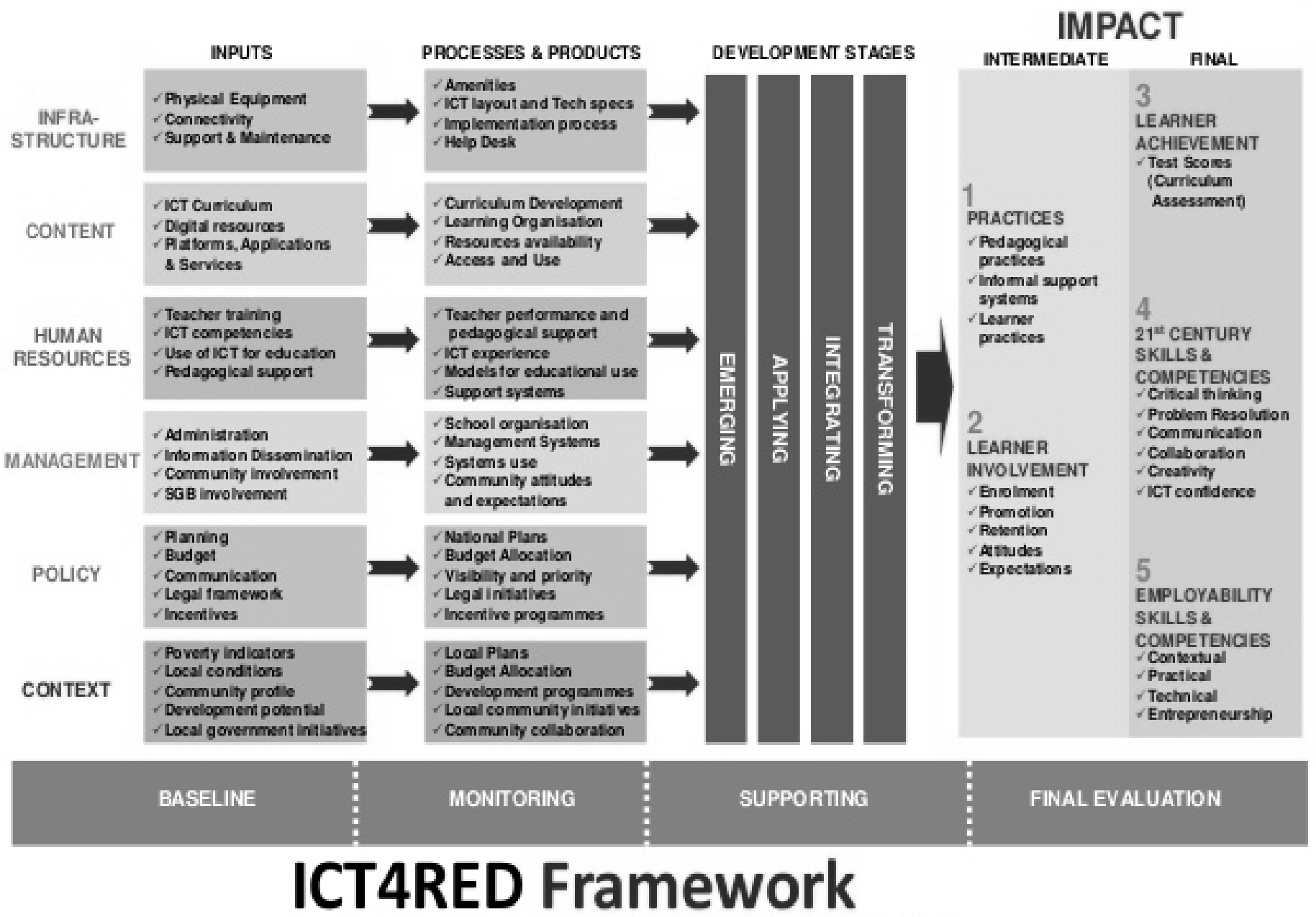

Amended hier-American Develipmert Bank (NB) Conceptual Framework

(Projects for the use of hformation and Communication Technologies in Education, 2010)

Figure 2: The ICT4RED monitoring and evaluation framework

Source: Herselman, M., \& Botha, A. (2014). Designing and implementing an Information

Communication Technology for Rural Education Development (ICT4RED) initiative in a resource constraint environment: Nciba school district, Eastern Cape, South Africa. CSIR, Pretoria, South Africa. 


\section{Exhibit 5: The ICT4RED Implementation process}

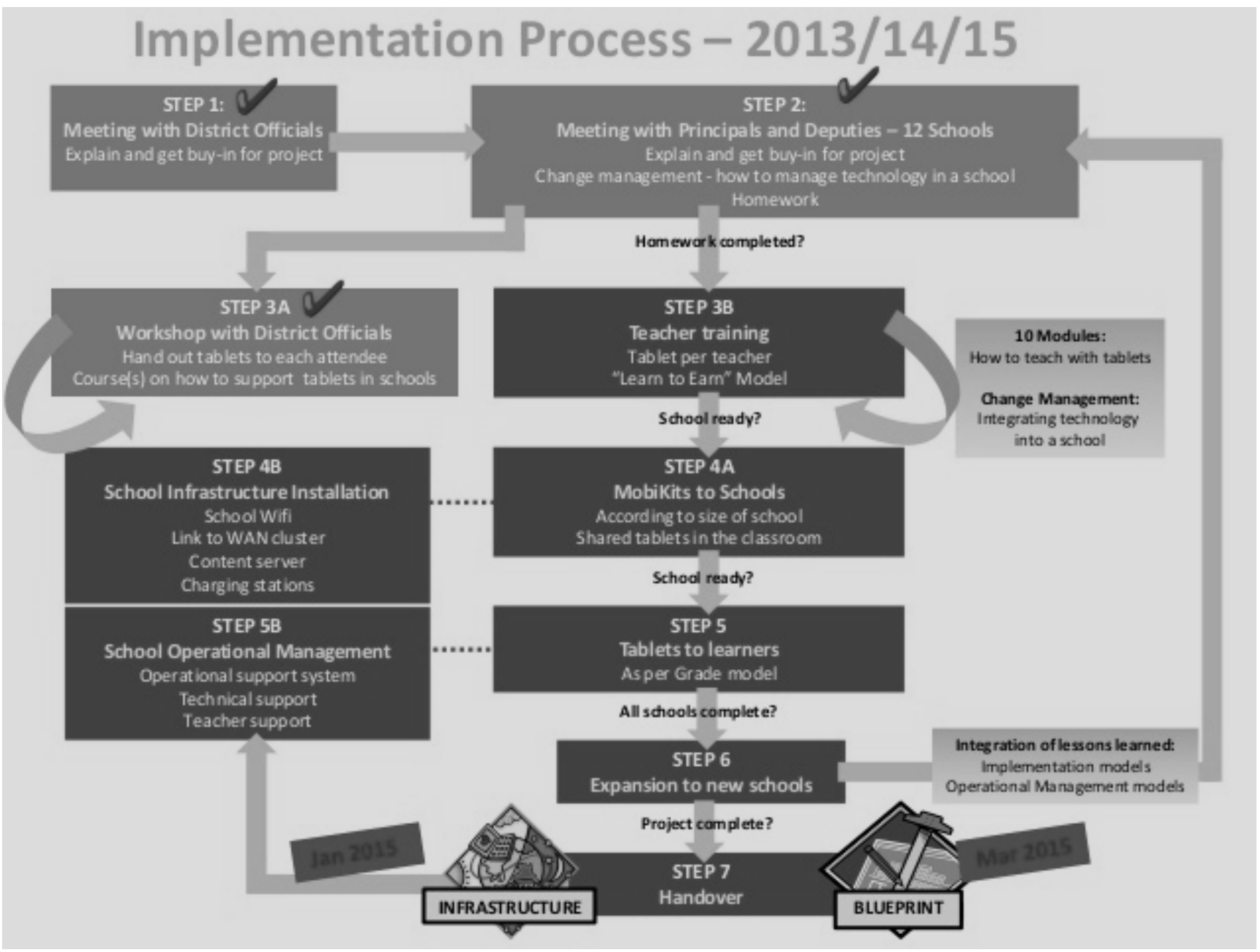

Figure 3: The ICT4RED Implementation process.

Source: Herselman, M., \& Botha, A. (2014). Designing and implementing an Information Communication Technology for Rural Education Development (ICT4RED) initiative in a resource constraint environment: Nciba school district, Eastern Cape, South Africa. CSIR, Pretoria, South Africa. 